\title{
Tumores em animais de produção: aspectos comparativos
}

\author{
Tumors in farm animals: comparative aspects
}

\author{
Adriano Tony Ramos ${ }^{I}$ Arlete Benta de Souza ${ }^{I I}$ Diego Mollerke Norte ${ }^{\mathrm{II}}$ \\ João Luiz Montiel Ferreira' ${ }^{\text {III }}$ Cristina Gevehr Fernandes ${ }^{\text {IV }}$
}

\section{RESUMO}

Com o objetivo de realizar um estudo retrospectivo de tumores em animais de produção (bovinos, ovinos, eqüinos e suínos), foi realizada uma revisão nos casos suspeitos de neoplasmas recebidos pelo Laboratório Regional de Diagnóstico da Faculdade de Veterinária da Universidade Federal de Pelotas num período de 24 anos (1978-2002). Os aspectos epidemiológicos dos neoplasmas nessas espécies foram relatados, e uma classificação concisa para padronizar a nomenclatura, seguindo padrões internacionais de classificação histológica de tumores, foi realizada. O estudo baseou-se em um universo de 6.267 materiais. Obtiveram-se 175 casos de tumores distribuídos entre as espécies bovina (98/4407), ovina (9/636), eqüina (65/774) e suína (3/450). Esses tumores foram então avaliados e reclassificados. Os dados referentes foram analisados quanto a sua prevalência por raça, sexo, idade $e$ localização anatômica (origem) do tumor. Os tumores com maior casuística foram os linfomas nos bovinos, os carcinomas de células escamosas nos bovinos e ovinos e os sarcóides nos eqüinos.

Palavras-chave: tumores, epidemiologia, bovinos, ovinos, eqüinos, suínos.

\section{ABSTRACT}

Aiming at a complete study on all neoplastic lesions in farm animals (cattle, sheep, horses and swine), a retrospective review was performed covering a 24 years period (1978-2002) at the Regional Diagnostic Laboratory of the Veterinary School in Pelotas, Southern Brazil. The analysis included the review of epidemiological data and the standardization of classification parameters considering current rules of international classification of tumors. Six thousand two hundred and sixty seven samples were analyzed. The distribution among the species was: 98 in cattle, 9 in sheep, 65 in horses and 3 in pigs, over
175 cases detected. Prevalence studies as for the breed, sex, age and anatomical distribution of the tumors were analyzed. Lymphoma in cattle, squamous cell carcinoma in cattle and sheep, and sarcoids in horses were the tumors with higher incidence.

Key words: tumors, epidemiology, cattle, sheep, horses, pigs.

\section{INTRODUÇÃO}

Dados sobre a prevalência de tumores em animais de produção são escassos. A freqüência de um tipo vem sendo estimada somente em termos gerais, ou pela comparação com a freqüência de outros tumores que ocorrem na mesma espécie (BEVERIDGE \& SOBIN, 1974).

A classificação de tumores em animais domésticos, baseada em critérios histológicos definidos, é necessária para evitar mal-entendidos na troca de informações entre profissionais da área e para a comparação epidemiológica e estudos terapêuticos. A maior parte das classificações é baseada na combinação de critérios histogenéticos (órgãos ou tecidos de origem), critérios histológicos (anatomia microscópica) e comportamento biológico (benignos ou malignos) (BEVERIDGE \& SOBIN, 1974; CULLEN et al., 2002).

Os tumores em bovinos podem ser divididos em: 1) tumores espontâneos do tipo congênito, que ocorrem em fetos, recém-nascidos e bezerros muito

\footnotetext{
IPrograma de Pós-graduação em Veterinária, Universidade Federal de Pelotas (UFPel), Pelotas, RS, Brasil.

IIFaculdade de Veterinária, UFPel, Pelotas, RS, Brasil.

IIILaboratório Regional de Diagnóstico (LRD), UFPel, Pelotas, RS, Brasil.

IV Departamento de Patologia Veterinária, Faculdade de Veterinária, UFPel, 96010-900, Pelotas, RS, Brasil. E-mail: cristina.gf@uol.com.br. Autor para correspondência.
} 
jovens (menos de dois meses); 2) tumores espontâneos do tipo juvenil, que ocorrem em bezerros mais velhos (2 a 12 meses); e 3) Tumores iatrogênicos, como os papilomas causados pelo papilomavírus após tatuagem ou descorna ou papilomas da pele e carcinomas de células escamosas após tatuagem com nitrogênio líquido. Este padrão de classificação visa a indicar a possível patogenia dos tumores em bezerros (MISDORP, 2002).

A diferença entre as várias classificações gera confusões em levantamentos epidemiológicos e em relatos de casos. A uniformização da nomenclatura é desejável para que dados epidemiológicos obtidos em regiões diferentes possam ser comparados e medidas terapêuticas ou preventivas possam, também, ser comparadas em diferentes centros de pesquisa (CULLEN et al., 2002). Acredita-se que, através de estudos retrospectivos, poderão ser obtidos dados importantes acerca do comportamento, da epidemiologia e etiologia de diferentes tumores (MISDORP, 1990).

O presente estudo teve por objetivo a revisão e a quantificação acurada da casuística de neoplasmas em bovinos, ovinos, eqüinos e suínos do Laboratório Regional de Diagnóstico (LRD) da Faculdade de Veterinária da UFPel, no período de 1978 a 2002. Adicionalmente, foi idealizado um compilado de dados regionais devido à inexistência de dados nacionais gerais sobre a prevalência de tumores nessas espécies de produção.

\section{MATERIAL E MÉTODOS}

Realizou-se o levantamento do banco de dados, lâminas histológicas e blocos de parafina do LRD - UFPel, abrangendo o período de 1978 a 2002. Buscou-se identificar os neoplasmas diagnosticados nas espécies bovina, ovina, eqüina e suína. Os dados (raça, sexo, idades e localização anatômica) foram tabulados e analisados.

A maioria do material analisado estava em blocos de parafina ou em lâminas histológicas. Alguns preparados histológicos foram descorados com ácido acético e recorados pela técnica de hematoxilina-eosina (HE). O material que estava em blocos de parafina foi cortado a 5 micrômetros, corado pela HE e examinado por microscopia de luz.

Sempre que necessário, foram empregadas técnicas de histoquímica (Gomori e Tricrômico de Masson) e de imunoistoquímica, para possibilitar o diagnóstico ou aumentar sua confiabilidade.

Nos procedimentos de imunoistoquímica, utilizaram-se como anticorpos primários anti-Glial
Fibrilary Acid Protein (GFAP), anti-citoqueratinas (AE1/ AE3) e anti-vimentina. A inativação da peroxidase endógena foi realizada com $\mathrm{H}_{2} \mathrm{O}_{2} 3 \%$, e a recuperação antigênica com tampão citrato $(\mathrm{pH} 8,0)$ em forno de microondas, por 15 minutos. O anticorpo primário foi incubado em câmara úmida por 12 horas e o secundário por uma hora. Na revelação, foi utilizado o cromógeno diaminobenzidina (DAB) e os cortes foram contracorados com hematoxilina de Harris.

A classificação histológica dos tumores foi baseada na Classificação Histológica de Tumores de Animais Domésticos da Organização Mundial da Saúde (OMS) e na classificação utilizada por MEUTEN (2002).

\section{RESULTADOS}

No período 1978 a 2002, foram recebidos 6.267 materiais na forma de cadáveres enviados para necropsia, peças de biopsia ou materiais específicos das espécies em estudo, para análise no LRD, e que foram destinadas a diferentes laboratórios (patologia, microbiologia, parasitologia e/ou virologia). Do total, 266 casos eram suspeitos de neoplasmas. A partir de todos esses materiais, foram resgatadas somente 175 neoplasmas. Dados desses tumores e dos animais portadores foram obtidos a partir do levantamento das fichas correspondentes a cada caso.

Constataram-se, então, 98 casos de neoplasma em bovinos, que representam 2,22\% do total de materiais recebidos (4.407); nove casos em ovinos que representam 1,41\% do total de materiais (636); 65 em eqüinos, que, dos 774 materiais dessa espécie, representam 8,39\%; e três em suínos, representando $0,6 \%$ de 450 materiais recebidos. Os tumores mais prevalentes, somadas todas as espécies, foram: o carcinoma de células escamosas (46), o linfoma (29) e o sarcóide eqüino (28). A pele e o tecido subcutâneo foram os sítios mais afetados (78).

Diagnósticos de leiomiossarcoma foram realizados com auxílio da coloração de tricrômico de Masson e imunoistoquímica para vimentina. Observouse a coloração vermelha das fibras musculares do leiomiossarcoma no tricrômico de Masson e marcação citoplasmática positiva das células tumorais.

A confirmação do diagnóstico de um plasmocitoma foi realizada com o auxílio de imunoistoquímica com marcação negativa para citoqueratinas (AE1/AE3), diferenciando-o de um carcinoma indiferenciado. O diagnóstico de schwanomas foi validado pelos resultados da imunoistoquímica fracamente positivos para GFAP e positivos para vimentina. A marcação imunoistoquímica negativa para citoqueratinas e positiva para GFAP confirmou o diagnóstico de ependimoma. 
Bovinos. Nos bovinos, uma parcela significativa dos tumores era de origem hematopoética (26/98), sendo todos linfomas. Carcinoma de célula escamosa (CCE) (6/17) foi o principal tipo de tumor epitelial (17/98). Dos tumores do sistema genital (13/ 98), o carcinoma de células escamosas vulvar (7/13) foi o mais prevalente nas fêmeas; nos machos (5/13), o fibropapiloma (4/5) do pênis e do prepúcio foi o mais importante. Entre os tumores de origem mesenquimal (10/98), os fibromas (5/10) foram os mais prevalentes. Em alguns casos (6/98), havia somente metástases de carcinomas de células escamosas localizadas em linfonodos parotídeo (3/6), submandibulares (2/6) e retrofaríngeos (1/6). Todos os tumores encontrados estão listados na tabela 1.

Quanto ao sexo, as fêmeas apresentaram um maior número de lesões (54\%), quando comparadas aos machos (25,5\%). Porém, em 20,5\% dos casos, não havia informações sobre o sexo do portador. As raças mais afetadas foram a Holandesa (21\%) e a Hereford (9\%). Porém, a raça não foi informada em 38\% dos casos (Tabela 2). Em aproximadamente 26,5\% dos casos, a idade não foi informada. Não houve diferença percentual significativa entre os grupos etários: jovens: zero a dois anos (25,5\%); adultos: 3 a 7 anos (23,5\%); idosos: acima de oito anos (24,5\%).

Ovinos. A maioria dos tumores foi de origem epitelial (5/9), com o carcinoma de células escamosas sendo o principal tipo tumoral (4/5). O outro caso era um papiloma. No sistema genital, o carcinoma de células escamosas vulvar foi o único tipo de tumor encontrado (2/2). Os demais tipos tumorais estão relatados na tabela 1.

Em um grande número de casos, o sexo do paciente não foi informado (44,5\%). Houve uma predominância de tumores localizados em fêmeas (33,3\%), quando comparadas com os machos (22,2\%). A raça mais afetada por neoplasmas foi a Ideal (33\%) (Tabela 2).

Quanto à distribuição etária, os animais adultos (dois a sete anos) foram os mais afetados (44,5\%), com relação aos jovens (zero a dois anos) $(22,5 \%)$ e aos idosos (mais de sete anos) (11\%).

Eqüinos. Os tumores de origem mesenquimal da pele e de tecidos moles representaram a maioria dos casos (34/65), sendo que o sarcóide eqüino foi o principal tipo de neoplasma encontrado (28/65). Nos tumores de origem epitelial e melanocítica (11/65), os carcinomas de células escamosas (6/11) e os papilomas (5/11) foram os únicos tipos tumorais encontrados nos eqüinos. Nos tumores do sistema genital (7/65), os carcinomas de células escamosas no pênis e prepúcio do macho (3/7) prevaleceram sobre os tumores das células da granulosa no ovário das fêmeas (2/7). Nos tumores de origem hematopoética (7/65), os plasmocitomas (2/7), juntamente com o mastocitoma e os linfomas (2/7), foram os tipos encontrados. A distribuição completa dos tumores em eqüinos está relatada na tabela 1 .

Com relação ao sexo, os machos representaram a maioria dos animais afetados por tumores (41\%), com relação às fêmeas (31\%). Em 28\% dos casos, o sexo do eqüino portador não foi informado. A raça mais afetada foi a Crioula, com 35\% dos casos de neoplasmas (Tabela 2).

Nos eqüinos jovens (zero a cinco anos), houve uma prevalência de tumores um pouco maior $(35,4 \%)$ que nos adultos (6 a 12 anos) $(26,1 \%)$ e que nos idosos (mais de 12 anos) (15,4\%), mostrando uma diminuição da prevalência com o aumento da idade.

Suínos. Dos três tumores diagnosticados, dois eram localizados no trato digestivo, sendo um adenocarcinoma gástrico e outro um fibroma na cavidade oral. Outro neoplasma identificado foi um melanoma, localizado no membro anterior (Tabela 1).

Os dois tumores do sistema digestivo ocorreram em fêmeas e o tumor do sistema tegumentar no macho. As raças afetadas foram Landrace, Duroc e um animal sem raça definida (Tabela 2). Os casos ocorreram em animais com pouca idade, dois casos ocorreram em animais com dois anos (adultos de dois a cinco anos) e um ocorreu em um animal com menos de um ano (jovem de zero a dois anos).

\section{DISCUSSÃO}

A falta de entendimento das várias faces de alguns tipos de tumores se dá devido à escassez de relatos de casos, em particular relatos de períodos longos, como estudos retrospectivos e acompanhamentos destes mesmos casos (DIXON \& HEAD, 1999).

Levantamentos de casuística em laboratórios de diagnóstico veterinário foram realizados na década de 50 e 60, abrangendo o período de 1934 a 1965, no Estado de Minas Gerais. Nesses levantamentos, estava incluída a prevalência de tumores em animais de produção. Os autores observaram que as porcentagens de tumores foram significativamente maiores em eqüinos (23,7\%) e bovinos (13,1\%), apesar de um menor número de materiais analisados dessas espécies (1.626 bovinos e 211 eqüinos). Não foram relatados tumores em ovinos. Em suínos, a prevalência foi semelhante à encontrada neste trabalho $(0,6 \%)$, apesar do maior número de materiais dessa espécie analisados nesses levantamentos (1.336). Dados como 
Tabela 1 - Tumores em animais de produção: aspectos comparativos. Tumores diagnosticados em cada espécie separados por sistema.

\begin{tabular}{|c|c|c|c|c|c|c|}
\hline Sistema afetado & Tipos de tumores & Bovinos & Eqüinos & Ovinos & Suínos & Total \\
\hline \multirow[t]{7}{*}{ Digestivo } & Total & 5 & 1 & 0 & 2 & 8 \\
\hline & Adenocarcinoma & - & - & - & 1 & 1 \\
\hline & Carcinoma & 1 & - & - & - & 1 \\
\hline & CCE & 2 & - & - & - & 2 \\
\hline & Fibroma & 1 & - & - & 1 & 2 \\
\hline & Fibrossarcoma & 1 & - & - & - & 1 \\
\hline & Lipoma & - & 1 & - & - & 1 \\
\hline \multirow[t]{2}{*}{ Endócrino } & Total & 1 & 0 & 0 & 0 & 1 \\
\hline & Carcinoma de córtex da adrenal & 1 & - & - & - & 1 \\
\hline \multirow[t]{9}{*}{ Genital } & Total & 18 & 7 & 2 & 0 & 27 \\
\hline & Adenocarcinoma de útero & 1 & - & - & - & 1 \\
\hline & CCE & 8 & 3 & 2 & - & 13 \\
\hline & Fibroleiomioma & 1 & - & - & - & 1 \\
\hline & Fibroma & - & 1 & - & - & 1 \\
\hline & Fibropapiloma* & 4 & 1 & - & - & 5 \\
\hline & Leiomiossarcoma & 1 & - & - & - & 1 \\
\hline & Papiloma & 1 & - & - & - & 1 \\
\hline & Tumor das células da granulosa & 2 & 2 & - & - & 4 \\
\hline \multirow[t]{4}{*}{ Hematopoético } & Total & 26 & 7 & 1 & 0 & 34 \\
\hline & Linfossarcoma & 26 & 2 & 1 & - & 29 \\
\hline & Mastocitoma & - & 3 & - & - & 3 \\
\hline & Plasmocitoma & - & 2 & - & - & 2 \\
\hline \multirow[t]{3}{*}{ Nervoso } & Total & 2 & 2 & 0 & 0 & 4 \\
\hline & Schwannoma & 1 & 2 & - & - & 3 \\
\hline & Ependimoma & 1 & - & - & - & 1 \\
\hline \multirow[t]{3}{*}{ Olho } & Total & 8 & 1 & 1 & 0 & 10 \\
\hline & CCE & 8 & - & 1 & - & 9 \\
\hline & Papiloma & - & 1 & - & - & 1 \\
\hline Pele e tecido subcutâneo & Total & 17 & 11 & 5 & 1 & 34 \\
\hline \multirow[t]{5}{*}{ epitel. e melanocíticos } & CCE & 6 & 6 & 4 & - & 16 \\
\hline & Melanoma & 3 & - & - & 1 & 4 \\
\hline & Melanoma fibromatoso & 3 & - & - & - & 3 \\
\hline & Papiloma & 4 & 5 & 1 & - & 10 \\
\hline & T. misto glând. sudorípara apócrina. & 1 & - & - & - & 1 \\
\hline Pele e tecido subcutâneo & Total & 10 & 34 & 0 & 0 & 44 \\
\hline \multirow[t]{8}{*}{ mesenquimais } & Adenocarcinoma & 1 & - & - & - & 1 \\
\hline & Fibroma & 5 & 3 & - & - & 8 \\
\hline & Fibrossarcoma & 1 & - & - & - & 1 \\
\hline & Hemangioma & - & 1 & - & - & 1 \\
\hline & Hemangiossarcoma & - & 2 & - & - & 2 \\
\hline & Leiomioma & 2 & - & - & - & 2 \\
\hline & Lipossarcoma mixóide & 1 & - & - & - & 1 \\
\hline & Sarcóide & - & 28 & - & - & 28 \\
\hline \multirow[t]{5}{*}{ Respiratório } & Total & 3 & 1 & 0 & 0 & 4 \\
\hline & Adenocarcinoma & 1 & - & - & - & 1 \\
\hline & Carcinoma broncogênico & 1 & - & - & - & 1 \\
\hline & CCE pulmonar & 1 & - & - & - & 1 \\
\hline & Sarcoma indiferenciado & - & 1 & - & - & 1 \\
\hline \multirow[t]{3}{*}{ Urinário } & Total & 2 & 1 & 0 & 0 & 3 \\
\hline & Adenocarcinoma renal & 2 & - & - & - & 2 \\
\hline & Nefroblastoma & - & 1 & - & - & 1 \\
\hline \multirow[t]{2}{*}{ Indeterminado } & Total & 6 & 0 & 0 & 0 & 6 \\
\hline & Metástases de CCE em linfonodos & 6 & - & - & - & 6 \\
\hline Total & & 98 & 65 & 9 & 3 & 175 \\
\hline
\end{tabular}

*em um caso, em bovino, o fibropapiloma era transmissível. CCE: carcinoma de células escamosas.

raça, sexo e idade dos animais não foram analisados nos relatos de RANGEL \& MACHADO (1948), MACHADO \& RANGEL (1950), MACHADO et al. (1954), LAMAS et al (1958), MACHADO et al. (1964) e COSTA et al. (1967).
No presente estudo, a casuística de neoplasmas em ovinos e suínos foi relativamente baixa (1,41 e $0,6 \%$ respectivamente), se comparada com a casuística em bovinos e eqüinos. MISDORP (1990) descreve que ovinos e suínos são, normalmente, 
Tabela 2 - Tumores em animais de produção: aspectos comparativos. Distribuição de casos por raça e sexo.

\begin{tabular}{|c|c|c|c|c|c|}
\hline \multirow{2}{*}{ Espécie } & \multirow{2}{*}{ Raça } & \multicolumn{3}{|c|}{ Sexo } & \multirow{2}{*}{ Total } \\
\hline & & $\mathrm{F}$ & M & $\mathrm{NI}$ & \\
\hline \multirow[t]{11}{*}{ Bovino } & Aberdeen Angus & 1 & 1 & - & 2 \\
\hline & Charolês & 1 & 3 & - & 4 \\
\hline & Cruza & 3 & 5 & 3 & 11 \\
\hline & Devon & 1 & - & - & 1 \\
\hline & Hereford & 7 & 3 & - & 10 \\
\hline & Holandês & 21 & - & 2 & 23 \\
\hline & Ibagé & 1 & 1 & 1 & 3 \\
\hline & Jersey & 4 & - & 1 & 5 \\
\hline & Limousin & 1 & - & - & 1 \\
\hline & Shorthorn & - & 1 & - & 1 \\
\hline & NI & 9 & 11 & 17 & 37 \\
\hline \multirow[t]{9}{*}{ Eqüino } & Apalloosa & - & 2 & - & 2 \\
\hline & Árabe & - & - & 1 & 1 \\
\hline & Crioulo & 8 & 12 & 3 & 23 \\
\hline & Percheron & - & - & 1 & 1 \\
\hline & Porter & - & 1 & - & 1 \\
\hline & PSI & 1 & 4 & - & 5 \\
\hline & Quarto de Milha & 4 & - & - & 4 \\
\hline & SRD & 3 & 6 & 1 & 10 \\
\hline & NI & 4 & 2 & 12 & 18 \\
\hline \multirow[t]{4}{*}{ Ovino } & Corriedale & - & - & 2 & 2 \\
\hline & Ideal & 1 & 1 & 1 & 3 \\
\hline & Ile de France & 2 & - & - & 2 \\
\hline & NI & - & 1 & 1 & 2 \\
\hline \multirow[t]{3}{*}{ Suíno } & Duroc & 1 & - & - & 1 \\
\hline & Landrace & 1 & - & - & 1 \\
\hline & SRD & - & 1 & - & 1 \\
\hline Total & & 74 & 55 & 46 & 175 \\
\hline
\end{tabular}

$\mathrm{NI}=$ não informado; $\mathrm{PSI}=$ puro sangue inglês; $\mathrm{SRD}=$ sem raça definida.

abatidos antes da meia-idade e, por isso, têm menor probabilidade de desenvolver tumores.

Existe um significativo aumento na freqüência de neoplasmas com o aumento da idade dos animais (CULLEN et al., 2002). A freqüência de tumores malignos em bovinos e eqüinos aumenta com a idade (MISDORP, 1990). Nos eqüinos, a prevalência diminuiu com a idade. A incidência dos tumores malignos nos bovinos aumentou com a idade e foi maior nos animais adultos. Nos adultos, os tumores ocorreram mais em animais com maior idade.

Os tumores em bezerros são raros e sua ocorrência indica provável natureza congênita
(MISDORP, 2002). Foram observados dois tumores que acometeram animais com menos de um ano de idade. $\mathrm{O}$ primeiro foi um ependimoma em um bezerro com dois meses de idade e o segundo era um carcinoma de células escamosas em um animal com seis meses de idade. De acordo com MISDORP (2002), o ependimoma estaria no grupo dos tumores espontâneos do tipo congênito e o carcinoma de células escamosas nos tipos iatrogênicos, ou seja, induzidos por descorna ou marcação. SANCHES et al. (2000) descrevem um caso de ependimoma em um bovino, fêmea de sete anos, no Sul do Brasil. Em São Paulo, CANDIOTO et al. (2005) descreve, dois casos em bovinos da raça Nelore, ambos com um ano de idade, sendo um macho e uma fêmea. Os ependimomas são raros em todas as espécies, porém ocorrem com maior freqüência em cães, gatos e bovinos (KOESTNER \& JONES, 2000).

Os linfomas são importantes, especialmente em bovinos, pois sua ocorrência está relacionada com as dimensões do rebanho, o que sugere haver uma predisposição genética para o desenvolvimento desses tumores. A forma mais comum de linfoma surge endemicamente em bovinos adultos com mais de dois anos. Esta forma atinge diversos sistemas do organismo e normalmente está associada à infecção pelo vírus da leucemia bovina (CARLSON, 1993). Somente 1 a $10 \%$ desenvolvem a forma tumoral da leucose (BRAGA \& VAN DER LAAN, 2001).

Em bovinos, o linfoma é mais comum em áreas de predomínio de produção de leite (JACOBS et al., 2002), porém os linfomas foram pouco importantes no levantamento de Minas Gerais (9) (RANGEL \& MACHADO, 1948; MACHADO \& RANGEL, 1950; MACHADO et al., 1954; LAMAS et al, 1958; MACHADO et al., 1964; COSTA et al., 1967). Não há prevalência por raça ou sexo. Diferenças de incidência entre as raças de carne e de leite se devem à maior diferença na média de idade e fatores de manejo (JACOBS et al., 2002). Neste levantamento, 46,2\% dos tumores ocorreram em animais de raças leiteiras e $23 \%$ em animais de raças de carne e, em $30,8 \%$ dos casos, a raça não foi informada. Quanto ao sexo, 15 casos ocorreram em fêmeas, quatro em machos e, em sete, não foi informado o sexo dos animais. $\mathrm{O}$ risco da ocorrência de linfomas aumenta com a idade e ocorrem dois picos de incidência. O primeiro em animais até 1 ano e o segundo em animais de cinco a oito anos (JACOBS et al., 2002). Na casuística encontrada, os linfomas se distribuíram mais expressivamente em animais de cinco a sete anos, com dez casos em animais dessas idades. Isso confirma a informação de JACOBS et al. (2002) de que o segundo pico, cinco a oito anos, é onde ocorre o maior número de casos. 
Em eqüinos, em que $8,39 \%$ dos materiais eram neoplasmas, devem ser levados em consideração os sarcóides, que são descritos como os principais tumores de pele dos eqüinos (GOLDSCHMIDT \& HENDRICK, 2002). A espécie eqüina é a segunda espécie com maior prevalência de tumores dentre as estudadas. Sarcóides são os tumores de pele mais comuns dos eqüinos e ocorrem em cavalos de qualquer idade. A maioria dos casos ocorre em animais com menos de quatro anos de idade (GOLDSCHMIDT \& HENDRICK, 2002). Neste estudo, observou-se que a incidência maior ocorre dos três aos sete anos de idade. Este foi o neoplasma mais prevalente em eqüinos, com 37\% dos diagnósticos. Não houve casos de sarcóide eqüino nos levantamentos de Minas Gerais (RANGEL \& MACHADO, 1948; MACHADO \& RANGEL, 1950; MACHADO et al., 1954; LAMAS et al, 1958; MACHADO et al., 1964; COSTA et al., 1967). Embora a raça Crioula tenha sido a mais afetada, acredita-se que isso se deva ao fato de que esta é a raça que predomina na região, pois não há relato de predisposição racial para qualquer neoplasma. DIXON \& HEAD (1999) descrevem, em um estudo retrospectivo de tumores da região nasal e paranasal, que a idade média de animais com tumores de origem glandular ou epitelial foi de 14 anos, e, para os tumores de origem fibro-óssea ou óssea, foi de quatro anos. Isto demonstra uma diferença de prevalência quanto à idade em função da origem das células tumorais.

Em suínos, os neoplasmas são raros, pois uma grande proporção da população é abatida ainda jovem. As neoplasias mais freqüentes são aquelas que afetam suínos jovens (SOBESTIANSKY et al., 1999). Neste estudo, foram encontrados mais neoplasmas em animais adultos (dois com dois anos de idade). Os animais eram provavelmente reprodutores, os quais são abatidos com idade mais avançada. Existem tendências hereditárias de suínos miniaturas (Sinclair e Hormel) e de suínos da raça Duroc desenvolverem melanomas (CULLEN et al., 2002). O melanoma detectado neste estudo afetou um suíno, sem raça definida, com 6 meses de idade, localizando-se no membro anterior na região da escápula. Esses tumores ocorrem com maior freqüência no flanco e na região posterior do corpo (SOBESTIANSKY et al., 1999).

Em suínos e ovinos, os tumores foram pouco expressivos, somente 1,41 e 0,6\% dos materiais recebidos em ovinos e suínos, respectivamente, eram neoplasias. Isso se deve ao abate ocorrer antes da meiaidade nessas espécies, como descrito por MISDORP (1990), embora tenham ocorrido vários casos de CCE em ovinos. Em bovinos, em que 2,22\% dos materiais recebidos eram neoplasmas, o CCE e os linfomas foram importantes. Esses dois tipos de tumores têm grande importância entre os neoplasmas da espécie bovina: primeiro por ser um dos mais prevalentes em áreas de produção leiteira, principalmente o carcinoma ocular, e ter origem por radiação solar (JACOBS et al., 2002), e o segundo por ter sua incidência relacionada com o vírus da leucose bovina (CARLSON, 1993). Os tipos tumorais prevalentes nos levantamentos de Minas Gerais foram o CCE (94) e o papiloma (23) (RANGEL \& MACHADO, 1948; MACHADO \& RANGEL, 1950; MACHADO et al., 1954; LAMAS et al, 1958; MACHADO et al., 1964 e COSTA et al., 1967), sendo o primeiro também o neoplasma mais importante neste estudo.

Em seis casos, os CCE foram encontrados somente em linfonodos. Embora não fosse possível determinar a localização primária desses tumores, as possibilidades são de que sejam tumores de globo ocular ou de trato digestivo superior. De fato, em dois casos, os linfonodos provinham de bovinos Hereford, nos quais o CCE no olho é comum. Nos levantamentos do Estado de Minas Gerais, o CCE do trato digestivo superior de bovinos teve uma prevalência significativa (34) (RANGEL \& MACHADO, 1948; MACHADO \& RANGEL, 1950; MACHADO et al., 1954; LAMAS et al, 1958; MACHADO et al., 1964; COSTA et al., 1967). Neste estudo, foram encontrados somente dois CCE do trato digestivo superior, ocorridos em animais originados do Estado de Santa Catarina, região de ocorrência de samambaia, assim como o Estado de Minas Gerais (TOKARNIA et al., 2000).

\section{AGRADECIMENTOS}

Os autores agradecem aos técnicos de laboratório João Francisco Nunes, pela confecção das lâminas de HE, e Rosária Helena Azambuja, pela realização da técnica de imunoistoquímica.

\section{REFERÊNCIAS}

BEVERIDGE, W.I.B.; SOBIN, L.H. Bulletin of the world health organization - International histological classification of tumors of domestic animals, v.50, n.1-2, p.1-8, 1974

BRAGA, F.M.; VAN DER LAAN, C.W. Leucose enzoótica bovina. In: RIET-CORREA, F. et al. Doenças de ruminantes e eqüinos. 2.ed. São Paulo: Varela, 2001. p.126-134.

CANDIOTO, C.G. et al. Ependimoma anaplásico em bovinos - descrição de dois casos. In: ENAPAVE 12., 2005, Belo Horizonte, MG. Anais... Belo Horizonte: FEPMVZ, 2005. V.57, supl.1, 130p. p.66.

CARLSON, G.P. Moléstias do sistema hematopoético e hemolinfático. In: SMITH, B.P. Tratado de medicina interna de grandes animais. São Paulo: Manole, 1993. p.1061-1118.

Ciência Rural, v.38, n.1, jan-fev, 2008. 
COSTA, W.R. et al. VI - Notas estatísticas de anatomia patológica veterinária em Minas Gerais, Brasil. Arq Esc Vet UREMG, v.19, p.129-138, 1967.

CULLEN, J.M. et al. An overview of cancer pathogenesis, diagnosis and management. In: MEUTEN, D.J. Tumors in domestic animals. 4.ed. Ames: Iowa State, 2002. Cap.1, p.03-44.

DIXON, P.M.; HEAD, K.W. Equine nasal and paranasal sinus tumours: part 2: a contribution of 28 case reports. Vet $\mathbf{J}$, v.157, p.279-294, 1999.

GOLDSCHMIDT, M.H.; HENDRICK, M.J. Tumors of the skin and soft tissues. In: MEUTEN, D.J. Tumors in domestic animals. 4.ed. Ames: Iowa State, 2002. Cap.2, p.45-118.

JACOBS, R.M. et al. Tumors of the hemolymphatic system. In: MEUTEN, D.J. Tumors in domestic animals. 4.ed. Ames: Iowa State, 2002. Cap.3, p.119-198.

KOESTNER, A.; JONES, T.C. Sistema nervoso. In: JONES, T.C. et al. Patologia veterinária. 6.ed. São Paulo: Manole, 2000. Cap.27, p.1281-1320.

LAMAS, J.M. et al. IV - Notas estatísticas de anatomia patológica veterinária em Minas Gerais. Arq Esc Vet UREMG, v.11, p.93-112, 1958.

MACHADO, A.V.; RANGEL, N.M. II - Notas estatísticas de anatomia patológica veterinária em Minas Gerais (Brasil). Bol Soc Bras Med Vet, v.18, p.41-45, 1949-1950.
MACHADO, A.V. et al. III - Notas estatísticas de anatomia patológica veterinária em Minas Gerais. Arq Esc Vet UREMG, v.7, p.71-81, 1954.

MACHADO, A.V. et al. V - Notas estatísticas de anatomia patológica veterinária em Minas Gerais, Brasil. Arq Esc Vet UREMG, v.16, p.375-417, 1964.

MEUTEN, D.J. Tumors in domestic animals. 4.ed. Ames: Iowa State, 2002. p.788.

MISDORP, W. General considerations. In: MOULTON, J.E. Tumors in domestic animals. 3.ed. Berkeley: University of California, 1990. Cap.1, p.1-22.

MISDORP, W. Tumours in calves: comparative aspects. J Comp Pathol, v.127, p.96-105, 2002.

RANGEL, N.M.; MACHADO, A. V. 1 - Notas estatísticas de anatomia patológica veterinária em Minas Gerais (Brasil). Bol Soc Bras Med Vet, v.17,p.41-59, 1948.

SANCHES, A.W.D. et al. Doenças do sistema nervoso central em bovinos no Sul do Brasil. Pesq Vet Bras, v.20, p.113-118, 2000 .

SOBESTIANSKY, J. et al. Clínica e patologia suína. Goiania: Art 3, 1999. 464p.

TOKARNIA, C.H. et al. Plantas tóxicas do Brasil. Rio de Janeiro: Helianthus, 2000. 310p. 